\title{
Announcing the 2019 JMSE Travel Awards for Postdoctoral Researchers and Ph.D. Students
}

\author{
Anthony S. Clare ${ }^{D}$
}

School of Natural and Environmental Sciences, Newcastle University, Newcastle upon Tyne NE1 7RU, UK; tony.clare@newcastle.ac.uk

Following the successful launch of the JMSE travel awards last year, this year's competition attracted over 40 applications. The standard was again very high. I would like to thank the Editors and Editorial Board members who helped in evaluating the applications.

I am pleased to announce the winners of the 2019 competition:

The postgraduate student awardee is Mr. Daniel M. Coffey (Figure 1a), a PhD student in the laboratory of Dr. Kim Holland at the University of Hawai'i at Mānoa. The successful postdoctoral applicant is Dr. Rebecca L. Morris (Figure 1b), a Research Fellow in the National Centre for Coasts and Climate (NCCC), at the University of Melbourne (Figure 1).

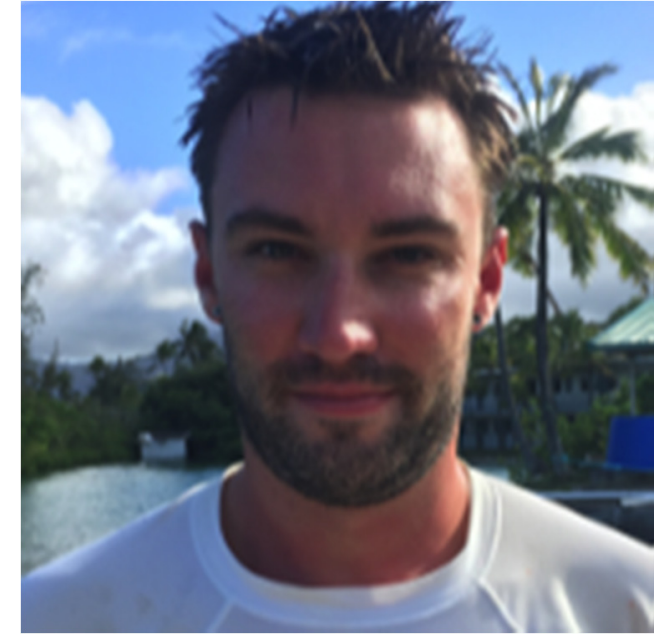

(a)

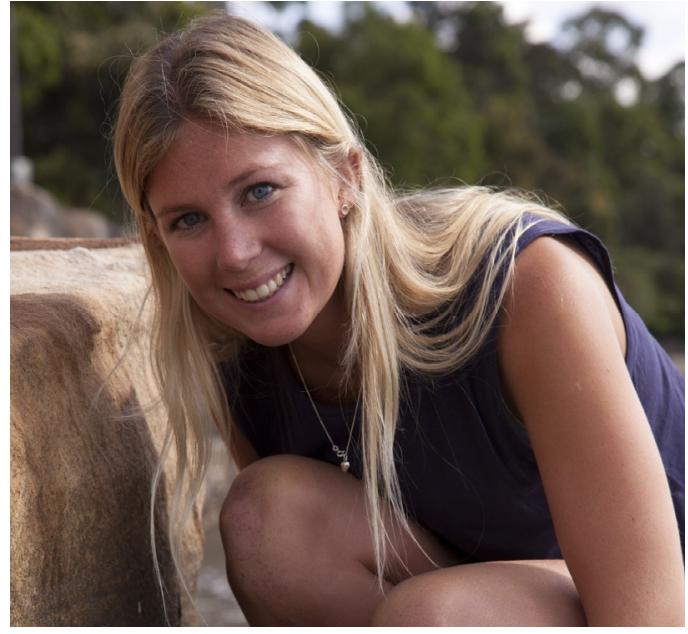

(b)

Figure 1. (a) Mr. Daniel M. Coffey; (b) Dr. Rebecca L. Morris.

Mr. Daniel Coffey's research uses biologging to investigate the physiology of a deepwater shark, Hexanchus griseus, in relation to environmental conditions, including in situ measurements of dissolved oxygen. Daniel has contributed to 10 peer-reviewed publications, including two as first author. He will use the travel award to attend the 2019 International Conference on Fish Telemetry (ICFT) in Arendal, Norway and present on: "Assessing performance and habitat suitability of a vertically migrating deepwater shark under a changing climate".

Dr. Rebecca L. Morris received her PhD in Marine Ecology in 2016 from the University of Sydney. She is now a Postdoctoral Research Fellow at the University of Melbourne where she works with Professor Stephen Swearer and leads the eco-engineering and restoration research theme within the NCCC. Dr. Morris has co-authored 13 peer-reviewed publications including six as first author. Dr. Morris will use her award to attend the 2019 Coastal and Estuarine Research Federation (CERF) 
Biennial Conference in Mobile, Alabama. Her oral presentation is entitled: "Designing nature-based coastal defence: what, where and how".

It is my pleasure on behalf of JMSE to congratulate Mr. Daniel Coffey and Dr. Rebecca Morris and wish them well with their presentations. I would also like to express my appreciation for MDPI's continued support of these travel awards.

(C) 2019 by the author. Licensee MDPI, Basel, Switzerland. This article is an open access article distributed under the terms and conditions of the Creative Commons Attribution (CC BY) license (http:/ / creativecommons.org/licenses/by/4.0/). 